\title{
UNSUR SOSIAL-BUDAYA DALAM NOVEL SURGA SUNGSANG KARYA TRIYANTO TRIWIKROMO SEBAGAI BAHAN PEMBELAJARAN DI SMA DAN MODEL PEMBELAJARANNYA
}

\author{
Eli Herlina \\ e-mail: eliherlina_3108@yahoo.com
}

Permasalahan yang menjadi pembahasan dalam penelitian ini dirumuskan sebagai berikut. (1) bagaimana unsur-unsur intrinsik novel Surga Sungsang karya Triyanto Triwikromo terkait tema, alur/ plot, penokohan, latar, dan sudut pandang? (2) bagaimana unsur-unsur ekstrinsik terkait sosial-budaya dalam novel Surga Sungsang karya Triyanto Triwikromo? (3) apakah novel Surga Sungsang karya Triyanto Triwikromo dapat dijadikan sebagai alternatif bahan pembelajaran sastra di SMA? (4) bagaimana model pembelajaran yang dapat digunakan untuk pembelajaran sastra di SMA terkait kajian unsur sosial-budaya dalam novel Surga Sungsang karya Triyanto Triwikromo? Berdasarkan masalah tersebut penelitian ini bertujuan untuk mendeskripsikan (1) unsur-unsur intrinsik novel Surga Sungsang karya Triyanto Triwikromo; (2) unsur-unsur ekstrinsik terkait sosial-budaya; (3) novel Surga Sungsang karya Triyanto Triwikromo sebagai alternatif bahan pembelajaran sastra di SMA; (4) mitra-mitra pembelajaran sebagai model pembelajaran untuk pembelajaran sastra di SMA.

Metode yang digunakan dalam penelitian ini adalah metode deskriptif kualitatif. Data penelitian berupa kata, frase, kalimat, ungkapan, serta peristiwa dalam novel Surga Sungsang karya Triyanto Triwikromo. Sumber data primer dalam penelitian ini yaitu novel Surga Sungsang karya Triyanto Triwikromo. Sumber data sekunder berupa buku-buku yang menunjang penelitian. Teknik pengumpulan data menggunakan teknik pustaka, simak dan catat. Teknik analisis data adalah metode pembacaan heuristik dan heurmenistik.

Berdasarkan hasil penelitian dapat disimpulkan (1) Unsur intrinsik novel Surga Sungsang karya Triyanto Triwikromo yaitu, tema utama dalam novel ini adalah perebutan kekuasaan, tema tambahan adalah kisah pembantaian. Alur yang digunakan dalam novel ini adalah jenis plot sorot-balik. Tokoh keseluruhan dalam novel ini mencerminkan manusia berwatak kompleks. Latar tempat dalam novel ini didominasi di Kampung Tanjung. Sudut pandang yang digunakan dalam novel ini adalah sudut pandang persona ketiga bersifat maha tahu. (2) Unsur sosial-budaya novel Surga Sungsang karya Triyanto Triwikromo yaitu, Unsur sosial berupa persaingan dan pertikaian. Unsur budaya dalam novel ini yaitu kebudayaan bersifat material berupa makam Syekh Muso, dan kebudayaan nonmaterial berupa adat istiadat warga Tanjung yang menganggap makam Syekh Muso sebagai makam keramat. (3) Novel Surga Sungsang karya Triyanto Triwikromo dapat dijadikan salah satu pilihan sebagai alternatif bahan pembelajaran sastra di SMA. (4) Mitra-mitra dalam pembelajaran dapat dijadikan sebagai pilihan model pembelajaran sastra di SMA.

\section{Kata kunci: Unsur sosial-budaya, novel Surga Sungsang karya Triyanto Triwikromo.}

PENDAHULUAN

Pembelajaran sastra di Indonesia
disajikan secara integratif pembelajaran bahasa Indonesia. Hal tersebut menimbulkan beberapa dampak seperti, ketidakseimbangan bobot materi dan cara penyajian antara bahasa dengan sastra, dan guru rata-rata lebih mengedepankan 
pembelajaran bahasa dari pada sastra. Padahal sastra mampu membuat siswa menjadi cerdas secara emosional, moral, sosial, dan sebagainya. Semi (2012: 5) mengatakan bahwa sebuh karya sastra tidak hanya dinilai sebagai sebuah karya seni yang memiliki budi, imajinasi, dan emosi, tetapi telah dianggap sebagai karya kreatif yang dimanfaatkan sebagai konsumsi intelektual. Secara kasat mata, pembelajaran sastra di sekolah terlihat hanya sekedar menumpang pada pelajaran bahasa saja. Pembelajaran bahasa disini dapat dikatakan pembelajaran mengenai tata bahasa dan berbagai keterampilan menulis praktis seperti suratmenyurat, membuat ringkasan, dan resensi. Sementara pembelajaran sastra hanya mencakup pantun, puisi, cerpen, prosa, dan drama (Arif, 2008).

Proses pembelajaran sastra melibatkan guru sastra sebagai pihak yang mengajarkan sastra, dan siswa sebagai subjek yang belajar sastra. Yang perlu diperhatikan adalah bagaimana upaya yang seyogyanya ditempuh agar siswa dapat belajar sastra dengan seefektif mungkin. Selain itu, yang juga menjadi salah satu penunjang keberhasilan pembelajaran sastra adalah bahan pembelajaran. Guru harus pintar dalam memilih dan mecari bahan ajar yang tepat untuk mengajarkan sastra di kelas, guru seharusnya tidak hanya berpusat pada buku pelajaran, guru dapat memanfaatkan referensi dari berbagai media seperti, media elektronik, media sosial, media cetak dan sebagainya, dengan kriteria yang tepat dan layak untuk disajikan pada siswa. Rahmanto (1988) menyebutkan ada tiga aspek yang tidak boleh dilupakan dalam memilih bahan pembelajaran sastra, yaitu bahasa, psikologi, dan latar belakang budaya. Salah satu contoh yang dapat dijadikan sebagai alternatif bahan pembelajaran sastra adalah novel.

Novel Surga Sungsang karya Triyanto Triwikromo merupakan salah satu novel yang memuat unsur sosial-budaya yang dikemas secara ringkas dengan bahasa luar biasa oleh pengarang yang pernah memperoleh Penghargaan Sastra 2009 Pusat
Bahasa untuk bukunya Ular di Mangkuk Nabi. Menurut Linda Christanty, pemeroleh Penghargaan Sastra Asia Tenggara-SEA Write Award-2013 menyatakan bahwa, "Cara Triyanto Triwikromo menyampaikan cerita begitu menarik. Surga Sungsang yang bercerita tentang Tanjung yang hendak tenggelam dan pergolakan tokoh-tokohnya melawan kekerasan serta memperjuangkan kebenaran membuat tak habis pikir bagaimana Ia bisa menulis cerita seperti itu".

Berdasarkan uraian di atas, peneliti berupaya untuk menggali unsur ekstrinsik terkait sosial-budaya dalam novel Surga Sungsang karya Triyanto Triwikromo. Peneliti juga berupaya mendeskripsikan apakah kajian terhadap novel Surga Sungsang tersebut dapat dijadikan sebagai alternatif bahan pembelajaran apresiasi sastra di SMA, serta bagaimana model pembelajaran yang tepat dalam pembelajaran sastra terkait kajian unsur sosial-budaya, sehingga dapat tercapainya tujuan pembelajaran.

\section{KAJIAN TEORI \\ Novel}

Novel merupakan salah satu karya sastra dari genre prosa yang menceritakan tentang kehidupan manusia dalam berinteraksi dengan lingkungan dan juga sesamanya. Nurgiyantoro (2010: 4) mengemukakan bahwa, "Novel sebagai sebuah karya fiksi menawarkan sebuah dunia, dunia yang berisi model kehidupan yang diidealkan, dunia imajinatif, yang dibangun melalui berbagai unsur intrinsiknya seperti peristiwa, plot, tokoh (dan penokohan), latar, sudut pandang, dan lainlain yang kesemuanya, tentu saja, juga bersifat imajinatif".

\section{Unsur Sosial-Budaya}

Unsur sosial merupakan bagian dari kehidupan bermasyarakat yang bersifat sosial berupa interaksi sosial. Interaksi sosial adalah proses antara individu dengan individu, individu dengan kelompok, dan 
kelompok dengan kelompok berhubungan secara timbal balik satu dengan yang lain. Sedangkan kebudayaan meliputi semua hasil cipta, karsa, rasa, dan karya manusia baik yang material maupun nonmaterial (baik yang bersifat kebendaan maupun yang bersifat kerohanian).

\section{Novel sebagai Alternatif Bahan Pembelajaran Sastra}

Novel dapat dijadikan sebagai salah satu alternatif bahan pembelajaran apresiasi sastra. Novel merupakan jenis bahan pembelajaran visual. Novel adalah salah satu karya sastra yang masih sangat digemari terutama oleh kalangan pelajar, dan masih terus mengalami perkembangan seiring berkembangnya zaman.

\section{Metode Penelitian}

Jenis penelitian yang digunakan adalah penelitian kualitatif. Penelitian kualitatif menurut Sukmadinata (2012: 60) adalah suatu penelitian yang ditujukan untuk mendeskripsikan dan menganalisis fenomena, peristiwa, aktivitas sosial, sikap, kepercayaan, persepsi, pemikiran orang secara individual maupun kelompok. Penelitian kualitatif merupakan metode penelitian yang berlandaskan pada filsafat positivisme, digunakan untuk meneliti pada kondisi objek yang alamiah (sebagai lawannya adalah eksperimen), yakni peneliti sebagai instrumen kunci, pengambilan sampel sumber data dilakukan secara porposive dan snowbaal, teknik pengumpulan data dengan tringgulasi (gabungan), analisis data bersifat induktif/ kualitatif, dan hasil penelitian kualitatif menekankan makna dari pada generalisasi (Sugiyono, 2011: 15).

\section{HASIL PENELITIAN}

\section{Analisis Unsur Intrinsik Novel Surga Sungsang Karya Triyanto Triwikromo}

\section{Tema}

Tema utama dalam novel Surga Sungsang karya Triyanto Triwikromo adalah perebutan kekuasaan.Cerita dalam novel
Surga Sungsang karya Triyanto Triwikromo banyak menggambarkan konflik dan pertikaian antartokoh demi kepentingan keegoisan masing-masing tokoh untuk dapat menguasai Kampung Tanjung. Tama tambahan dalam Novel Surga Sungsang karya Triyanto Triwikromo adalah kisah pembantaian. Novel Surga Sungsang selain meceritakan tentang perebutan kekuasaan juga terdapat kisah pembantaian yang dilakukan oleh orang-orang yang menganggap dirinya paling suci, mereka membantai siapapun yang dianggap sebagai pemuja iblis dan pembela para pembenci Allah.

\section{Alur/ Plot}

Alur atau plot yang digunakan Triyanto Triwikromo dalam novel Surga Sungsang adalah jenis plot sorot-balik. Urutan kejadian yang dikisahkan dalam novel Surga Sungsang tidak bersifat kronologis, cerita tidak dimulai dari tahap awal (yang benar-benar merupakan awal cerita secara logika), melainkan dari tahap akhir, baru kemudian tahap awal cerita dikisahkan. Skema plot Surga Sungsang karya Triyanto Triwikromo dapat digambarkan sebagai berikut.

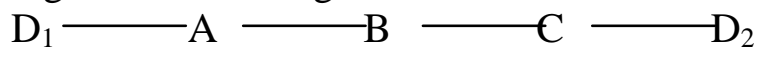

\section{Penokohan \\ Tokoh Utama}

a) Panglima Langit Abu Jenar

Panglima langit Abu Jenar adalah tokoh yang banyak dikisahkan dalam novel Surga Sungsang karya Triyanto Triwikromo. Abu Jenar adalah tokoh yang ingin menguasai Kampung Tanjung, sosok yang memiliki sifat antagonis. Datang ke Tanjung untuk berkuasa dan menjadi syekh baru yang disegani dan ditakuti warga Tanjung.

b) Kiai Siti

Kiai Siti adalah sesepuh Kampung Tanjung yang dihormati dan disegani warga karena sosoknya yang santun. Kiai Siti masih keturunan Syekh Muso yang kini menjadi tetuah Kampung Tanjung. 
c) Zaenab

Penjaga Makam Keramat Syekh Muso, perempuan yang seluruh tubuhnya bersisik dan lidahnya bercabang, sosok yang selalu tafakur sepanjang hari dan sepanjang malam.

\section{Tokoh Tambahan}

a) Kufah

Kufah adalah cucu Kiai Siti yang masih sangat polos, gadis sebelastahunan yang belum dapat mencerna banyak apa yang dikatakan orang-orang dewasa disekitarnya.

\section{b) Rajab}

Rajab adalah pemuda kampung yang dibenci Warga Tanjung karena sikapnya yang semena-mena setiap bertindak, dikenal sebagai berandal Kampung.

c) Teratai Hijau

Teratai Hijau adalah salah satu pimpinan orang kota yang ingin menguasai Tanjung untuk menjadikannya sebagai resor. Orang yang mengirim beberapa suruhan untuk menghancurkan Tanjung dan membunuh Panglima Langit Abu Jenar.

d) Widanti

Salah satu suruhan Teratai Hijau yang di tugaskan ke tanjung untuk membunuh Abu Jenar. Merupakan sosok yang polos, bertindak tanpa berpikir panjang terlebih dahulu.

e) Khadijah

Tukang perahu yang menyeberangkan para peziarah. Sosok yang ramah. Ramah terhadap semua orang yang diantarkannya untuk menyebrang, juga ramah pada lingkungan disekitarnya.

\section{f) Syekh Muso}

Tokoh yang dianggap sebagai panutan oleh warga, dianggap sebagai wali kesebelas, dan dianggap sebagai pendiri kampung tanjung.

g) Syekh Bintoro

Saudara kembar Syekh Muso yang ingin menyingkirkan dengan membunuh Syekh Muso.

h) Azwar (Ayah Kiai Siti)

Azwar adalah ayah Kiai Siti yang juga merupakan sesepuh dan tetuah Kampung yang dihormati warga Tanjung. Seseorang yang pada masanya menjadi incaran pembantaian oleh orang-orang dari Kampung sebelah.

i) Jibril, Khidir, dan Izrail

Tiga lelaki suruhan dari kota yang akhirnya benar-benar membakar Tanjung dengan seluruh isi tanpa rasa bersalah dan penyesalan. Tiga orang yang seolah tidak lagi memiliki rasa kemanusiaan.

\section{4) Latar (Setting)}

Latar tempat dalam cerita novel Surga Sungsang karya Triyanto Triwikromo hampir seluruhnya berada di Kampung Tanjung, di makam Syekh Muso, masjid, dan latar lainnya yaitu di kota, tepatnya di sebuah kafe. Latar waktu yang ditampilkan dalam novel Surga Sungsang karya Triyanto triwikromo, tidak ditampilkan secara jelas dan terperinci dari awal cerita. Hanya beberapa saja yang ditampilkan dalam cerita. Latar sosial dalam novel Surga Sungsang karya Triyanto Triwikromo adalah gambaran sosial masyarakat Tanjung yang memiliki adat dan kebiasaan yang cukup unik. Masyarakat Tanjung yang sangat meyakini makam Syekh Muso sebagai makam keramat, masyarakat tanjung yang menganggap bangau sebagai hewan suci, dan menganggap haram merusak pohon bakau.

\section{5) Sudut Pandang}

Sudut pandang yang digunakan dalam novel Surga Sungsang karya Triyanto Triwikromo adalah sudut pandang persona ketiga, cerita mempergunakan kata "dia" dan nama orang. Termasuk dalam sudut pandang bersifat mahatahu, karena cerita dikisahkan dari sudut "dia", namun dapat menceritakan apa saja hal-hal yang menyangkut tokoh "dia" tersebut.

\section{Unsur Sosial-Budaya dalam Novel Surga Sungsang Karya Triyanto Triwikromo}

\section{Unsur Sosial}

Unsur sosial dalam novel Surga Sungsang karya Triyanto Triwikromo berupa konflik-konflik sosial antartokoh dalam novel. Konflik-konflik sosial tersebut berupa persaingan dan pertikaian antartokoh, konflik 
tersebut terjadi akibat perebutan kekuasaan atas Kampung Tanjung, yaitu orang kota yang ingin menguasai Tanjung karena ingin menjadikannya sebagai resor. Namun dibalik itu, Panglima Langit Abu Jenar yang awalnya merupakan salah satu suruhan orang kota untuk membujuk warga Tanjung agar pindah dari Tanjung, ternyata diam-diam juga ingin menguasai Tanjung sendiri, dengan tujuan ingin menjadi Syekh baru di Kampung Tanjung, menjadi orang yang paling dihormati di Tanjung.

\section{Unsur Budaya}

Unsur budaya dalam novel Surga Sungsang karya Triyanto Triwikromo terdapat dua jenis kebudayaan, yaitu kebudayaan bersifat material dan kebudayaan nonmaterial. Kebudayaan yang bersifat material berupa makam Syekh Muso, sebuah makam yang dianggap sebagai makam dari seseorang yang telah membangun Kampung Tanjung. Kebudayaan nonmaterial berupa adat istiadat orang-orang Kampung Tanjung yang menganggap keramat makam Syekh Muso yang dipercaya telah membangun Kampung Tanjung selama tujuh hari. Warga menganggap Syekh Muso sebagai Wali Kesebelas.

\section{Bahan Pembelajaran Sastra di SMA}

Ditinjau dari kriteria pemilihan bahan dalam novel Surga Sungsang karya Triyanto Triwikromo, tiga aspek penting yang tidak boleh dilupakan dalam memilih bahan pengajaran sastra.

\section{Bahasa}

Bahasa yang digunakan sesuai dengan tingkat penguasaan bahasa di SMA. Bahasa seluruhnya sangat mudah dipahami, karena menggunakan bahasa sehari-hari. Namun, ditata oleh pengarang begitu rapih dengan beberapa kata-kata istilah yang digunakan sehingga bahasa terdengar puitis, sehingga membuat imajinasi siswa berkembang.

2. Psikologi

Novel Surga Sungsang sangat sesuai dengan tingkat kematangan jiwa anak-anak
SMA. Banyak sekali menggambarkan dan menceritakan hal-hal yang di luar nalar. Dengan begitu, siswa atau pembaca di ajak untuk berimajinasi untuk dapat memahami kejadian-kejadian dalam cerita tersebut.

\section{Latar Belakang Budaya}

Novel Surga Sungsang karya

Triyanto Triwikromo latar belakang budayanya yaitu unsur sosial berupa pertikaian dan parsaingan dalam memperebutkan lahan yang sudah ditempati untuk kepentingan lain, dengan berusaha membujuk orang-orang yang telah lama menempati lahan tersebut untuk pindah ke tempat lain.

\section{Model Pembelajaran Novel Surga Sungsang karya Triyanto Triwikromo di SMA}

\section{Kelompok Model Pengajaran Sosial}

\section{Mitra-mitra dalam Pembelajaran}

Berpasangan menuju investigasi kelompok. Asumsi yang mendasari pengembangan pembelajaran kooperatif (cooperative learning) adalah sebagai berikut:

a) Sinergi yang ditingkatkan dalam bentuk kerjasama akan meningkatkan motivasi yang jauh lebih besar dari pada dalam bentuk lingkungan kompetitif individual.

b) Anggota-anggota kelompok kooperatif dapat saling belajar satu sama lain.

c) Interaksi antaranggota, akan menghasilkan aspek kognitif semisal kompleksitas sosial, menciptakan sebuah aktivitas intelektual yang dapat mengembangkan pembelajaran ketika dibenturkan pada pembelajaran tunggal.

d) Kerja sama meningkatkan perasaan positif terhadap satu sama lain, menghilangkan pengasingan dan penyendirian, membangun sebuah hubungan, dan memberikan sebuah 
pandangan positif mengenai orang lain.

e) Kerja sama meningkatkan penghargaan diri, tidak hanya melalui pembelajaran yang terus berkembang, namun juga melalui perasaan dihormati dan dihargai oleh orang lain dalam sebuah lingkungan.

f) Siswa yang mengalami dan menjalani tugas serta merasa harus bekerjasama dapat meningkatkan kapasitasnya untuk bekerjasama secara produktif.

g) Siswa, termasuk juga anak-anak, bisa belajar dari beberapa latihan untuk meningkatkan kemampuan mereka dalam bekerja sama.

Manfaat yang paling menarik dalam prosedur kerja sama adalah campuran dengan model-model sosial lain, sebagai upaya untuk mengombinasikan efek dari beberapa model.

\section{SIMPULAN}

Berdasarkan hasil penelitian dan analisis yang dilakukan oleh penulis terhadap unsur sosial-budaya dalam novel Surga Sungsang karya Triyanto Trowikromo, dapat disimpulkan sebagai berikut.

1) Unsur intrinsik dalam novel Surga Sungsang karya Triyanto Triwikromo:

a) Tema utama dalam novel ini adalah perebutan kekuasaan, mengisahkan tentang pertikaian antartokoh yang memperebutkan Kampung Tanjung untuk tujuan yang berbeda. Sedangkan tema tambahan dalam novel ini adalah kisah pembantaian, menceritakan tentang kisah pembantaian pada masa kecil Kiai Siti yang dilakukan oleh orang-orang yang menganggap dirinya paling suci.

b) Alur atau plot yang digunakan dalam novel ini adalah jenis plot sorotbalik, urutan kejadian yang dikisahkan dalam novel tidak bersifat kronologis. c) Tokoh keseluruhan dalam novel ini mencerminkan manusia berwatak kompleks artinya ada yang berubah baik, buruk, keras kepala, pantang menyerah, dan lain-lain.

d) Latar tempat dalam novel ini didominasi di Kampung Tanjung, hampir keseluruhan cerita ada di Tanjung yang merupakan kampung yang menjadi incaran kekuasaan.

e) Sudut pandang yang digunakan dalam novel ini adalah sudut pandang persona ketiga, cerita mempergunakan kata "dia" dan nama orang. Termasuk dalam sudut pandang bersifat mahatahu, karena cerita dikisahkan dari sudut "dia", namun dapat menceritakan apa saja hal-hal yang menyangkut tokoh "dia" tersebut.

2) Unsur sosial-budaya dalam novel Surga Sungsang karya triyanto triwikromo:

a) Unsur sosial dalam novel ini berupa konflik-konflik sosial antartokoh dalam novel, berupa persaingan dan pertikaian. Persaingan orang-orang yang ingin menguasai Tanjung, dan pertikaian berupa keinginan saling membunuh dan memusnahkan atas dasar egoisme masing-masing.

b) Unsur budaya dalam novel ini terdapat dua jenis kebudayaan, yaitu kebudayaan bersifat material dan kebudayaan nonmaterial. Kebudayaan material berupa makam Syekh Muso, dan kebudayaan nonmaterial berupa adat istiadat warga Tanjung yang menganggap makam Syekh Muso sebagai makam keramat.

3) Hasil dari penelitian ini, penulis dapat menyimpulkan bahwa novel Surga Sungsang karya Triyanto Triwikromo dapat dijadikan salah satu pilihan sebagai alternatif bahan pembelajaran sastra di SMA. Hal ini dapat dilihat pada unsurunsur intrinsik dan unsur sosial-budaya yang memenuhi syarat atau kriteria dalam pemilihan bahan pembelajaran 
sastra di SMA yang terdiri dari tiga aspek penting yaitu bahasa, psikologi, dan latar belakang budaya. Bahasa yang digunakan sesuai dengan tingkat penguasaan bahasa di SMA, bahasa seluruhnya sangat mudah dipahami karena menggunakan bahasa sehari-hari. Novel ini banyak sekali menggambarkan dan menceritakan hal-hal yang di luar nalar, sehingga siswa atau pembaca di ajak berimajinasi untuk dapat memahami kejadian-kejadian dalam cerita tersebut. Novel ini juga memiliki latar belakang budaya berupa unsur sosial-budaya yaitu pertikaian dan parsaingan dalam memperebutkan lahan yang sudah ditempati untuk kepentingan lain, dan adat istiadat berupa mengeramatkan makam, hal tersebut masih sering dijumpai dalam kehidupan sehari-hari siswa.

4) Kelompok model pengajaran sosial berupa mitra-mitra dalam Pembelajaran dapat dijadikan sebagai pilihan model pembelajaran sastra di SMA yang efisien dalam pembelajaran terkait unsur sosialbudaya dalam novel Surga Sungsang karya Triyanto Triwikromo karena model pembelajaran tersebut dikembangkan untuk membantu siswa bekerja sama secara efektif, siswa dapat saling belajar satu sama lain.

\section{DAFTAR PUSTAKA}

Aminuddin. 2011. Pengantar Apresiasi Karya Sastra. Bandung: Sinar Baru Algensindo.

Aslichati, Lilik. 2011. Metode Penelitian Sosial. Jakarta: Universitas Terbuka.

Departemen Pendidikan Nasional. 2008. Kamus Besar Bahasa Indonesia. Jakarta: Balai Pustaka.

Endraswara, Suwardi. 2013. Metodologi Penelitian Sastra. Jakarta: Buku Seru.
Faruk. 2013. Pengantar Sosiologi Sastra. Yogyakarta: Pustaka Pelajar.

Joyce, Bruce, dkk. 2011. Models of Teaching Model-Model

Yogyakarta: Pustaka Pelajar.

Mulyawan, Budi dan Murip Yahya. 2008. Ilmu Sosial dan Budaya Dasar. Indramayu: Unwir Press.

Nurgiyantoro, Burhan. 2010. Teori Pengkajian Fiksi. Yogyakarta: Gadjah Mada University Press.

Purba, Antilan. 2010. Sastra Indonesia Kontemporer. Yogyakarta: Graha Ilmu.

Rasyidi, Ikhwan dkk. 2010. Analisis Teks Sastra. Yogyakarta: Graha Ilmu.

Saryono, Djoko. 2009. Dasar Apresiasi Sastra. Yogyakarta: Elmatera.

Semi, Atar. 2012. Metode Penelitian Sastra. Bandung: Angkasa.

Siswantoro. 2010. Metode Penelitian Sastra. Yogyakarta: Pustaka Pelajar.

Sugiyono. 2011. Metode Penelitian Pendidikan. Bandung: Alfabeta.

Susanto, Dwi. 2011. Pengantar Teori Sastra. Yogyakarta: Buku Seru.

Syamsuddin dkk. 2011. Metode Penelitian Pendidikan Bahasa. Bandung: Remaja Rosdakarya.

Tarigan, Henry Guntur. 2011. PrinsipPrinsip Dasar sastra. Bandung: Angkasa.

Triwikromo, Triyanto. 2014. Surga Sungsang. Jakarta: Gramedia Pustaka Utama. 